\title{
Reform on the Teaching Method of the Course of Satellite Communication
}

\author{
Rong Li \\ School of Communication and Information Engineering \\ Xi'an University of Science and Technology \\ Xi'an, China, 710054 \\ cold3000@126.com
}

\begin{abstract}
Satellite communication is an important major course of communication engineering which introduces the basic theory of satellite communication system. The paper firstly discusses some problems in course of traditional teaching including talking and writing on the blackboard, old multimedia course and outdated experiments. Secondly, new teaching methods called "three-dimensional method" and "inquiry teaching" are brought forward in order to solve the problems. Then, the application of new methods to the teaching of this course is discussed in detail. Obviously, they have some advantages over those traditional methods. Finally, the assessment results are narrated in Table 1 . In a word the new methods can improve students to think and learn actively.
\end{abstract}

Keywords—satellite communication; reform of teaching; threedimensional method; inquiry method

\section{INTRODUCTION}

Satellite communication is an important major course of communication engineering which is a key specialty in our university. And the course is regarded as a key profession subject for an electrical engineer. It is difficult for students because of its characteristics such as strength theory, many mathematical equations, a few of abstract conceptions, little actual contact [1]. Therefore, we should explore some new teaching methods of the course in order to improve the quality of teaching, the teaching effect and the students' abilities to analyze and solve problems.

\section{THE CHARACTERISTICS OF SATELLITE COMMUNICATION THEORY}

Satellite communication is a professional major course which presents the basic conception of satellite communication system and discusses the basic principles and techniques. The course includes basic concepts, channel modes, communication structure, Multiple access mode, modulation and demodulation, system design and so on [1]. Through the study of the course the student should understand the basic conception of satellite system, master the key techniques of satellite communication and can analyze a complete satellite system. Now its theory teaching is 32 hours which is not enough to grasp the key theory for the students.

\section{THE ANALYSIS OF TRADITIONAL METHODS}

Now the traditional teaching methods have some problems as follows: many teachers apply the traditional methods such as talking and writing on the blackboard.

The multimedia course now used is the replica of the textbook which lists large section words. Although experiment assisted instruction is applied, the experiment content is mainly to verify and students are passive without enthusiasm. Exercises after class Examples and exercises after class are the application of one knowledge point which seldom involves the comprehensive knowledge, so the students' abilities of comprehensive analysis are not improved.

Although experiment assisted instruction is applied, the experiment content is mainly to verify and students are passive without enthusiasm. The experiments of MATLAB are mostly to write programs and programming language is boring. Therefore, the students can not realize the real role of the computer software in simulation of satellite communication system. It is not conducive to train the innovation abilities of students and to improve their professional qualities [2].

\section{THREE-DIMENSIONAL AND INQUIRY METHOD}

According to three-dimensional method the information transfer and relationship between teachers and students are not unidirectional but bidirectional and comprehensive. The method lets students improve the enthusiasm in learning. It includes observing by eyes, discussion by mouths, perceptual experience by ears, thinking intuitively by head and operating by hands based on the theory of the mode of target teaching.

The mode of inquiry teaching is a new exploration. Firstly, teachers select and confirm the research issues according to the teaching contents, creating a problem situation similar to the academic research, then let students find the questions by reading, observation and experiments. Furthermore, applying some methods such as investigation, test and operation, students will solve the questions by some exploration activities, such as discussion and communication. Finally, the knowledge and abilities of students will be improved, especially in the areas of searching and innovation. 


\section{THE APPLICATION}

The three-dimensional and inquiry teaching methods are innovative and they fully use the existing information technology. The methods including interaction between teachers and students and communication between students will be taken in order to achieve the desired effect. The application is listed as follows:

\section{A. Creating Situation and Proposing Questions}

The creation of problem situation is important for inquiry teaching. The situation is that teachers set up the conflicting and suspicious teaching environment in order to guide students to study a question. The creation of problem situation can not only cause students to think but also inspire the exploration interests and the strong thirst for knowledge of students.

In the teaching course of this curriculum, the author divided every teaching key part into several modules in terms of the major knowledge which students have mastered.

\section{B. New multimedia courseware and Matlab/Simulink simulation software}

In order to mobile the enthusiasm of students and achieve the interaction some software are used such as JAVA and CAI to design new multimedia course-ware [3]. The new courseware has distinct interface for students. Flash is applied to describe the abstract content by the vivid animation.

Moreover, Matlab/Simulink simulation software is applied in course of teaching to simulate some parts of satellite communication system. Simulink of Matlab is a dynamic simulation platform supplied by Math Works Corporation. A complex simulation model is constructed by module blocks so that users can get rid of the pressure of mathematical deduction and the worry of programming. Thus, the observation of the system working principles can be concentrated on.

\section{Online teaching platform and Teaching practice base}

Our university has two campuses, one is in Xi'an and the other is in Linton. Most students are in Linton, so that it is very inconvenient for relationship between teachers and students because teachers live in Xi'an. When students have problems teachers often cannot solve them immediately. According to the actual situation an online teaching platform (BBS section) has been built. Students can ask questions on BBS when they have difficulties in course of teaching and teachers will reply them as soon as possible. In the future, we will fully apply internet techniques to the online platform based on BBS so that we will interact with students and solve the problems of students immediately.

The practice teaching is the effective supplement of classroom teaching, which will improve the comprehensive abilities of students. In order to further understand the content of this course the rich resources of apparatus of corporations can be used to build the teaching practice base.

Firstly, in order to let students grasp the basic principles of digital television system we contacted the Xi'an Broadcast and Television Center and supplied an opportunity for students to visit. In course of visit students understand the whole working process by the introduction of engineers. They have further conception of communication system based on the basic theory and asked several questions about the working principle. They wrote practice reports after the visit. From the reports we can see that the interest of students was improved by the visit.

On basis of visit we also contacted some corporations such as Sichuan Changhong Electronics Corporation, Qinling Power Plant and Dragon Communication Corporation of Luoyang to set up practice bases in which students can do production practice. In course of practice students can see the working process of the digital television system equipment and the construction and working principle of digital television system. By the theory with practice students can analyze the principles and technical characteristics of equipment and do some demonstration experiments in the guidance of technical staff. The mode of practice is completely different from classroom teaching and students can practice by hands. Through the further production practice the practical abilities of students can be improved and it is benefit for students to deeply understand the theory.

\section{Introduction by Teachers and Exploration by Students}

In the course of teaching the situation of active inquiry and cooperation for students should be created. Students should be encouraged to think and attempt boldly so that their creative think can be inspired.

Teachers should enlighten students to think reasonably and reveal the relationship between known and future on the basis of the known cognitive levels of students. Thus the information provided by questions can be analyzed [4].

In course of the curriculum the author always emphasized that the satellite communication is the digital communication system in essence, so modulation and demodulation techniques are very important. Then the author let students complete the simulations of QPSK and 16QAM by Matlab based on their grasped professional knowledge. After finishing simulations the results should be analyzed to get the conclusion. In a word, students can deeply understand the aim and essence of modulation by active inquiry and analyze the advantages and disadvantage of the different modulation types.

Students should be induced to reflect continuously during the inquiry. Firstly, the inquiry theory should be concluded to construct the mathematical module and methodology. Secondly, the reflection should done in course of inquiry and let students experience the interests of discovery and re-creation. Then students' abilities of exploration and application can be improved. In course of teaching teachers should induce students to think some questions including what, why, how to choice, optimization and better method. By doing these, the reflection consciousness and habits of students can be developed.

Teachers should encourage students to conclude for the exploration activity at the end of the inquiry teaching and evaluate the results. The assessment is the final part of the inquiry teaching. It is the end of this activity and next inquiry course may be breaded. 
Therefore, the work of assessment is very important. To ensure the just and comprehensiveness of assessment diversification should be done about the evaluation dimension and methods. The "Three-dimension" mode can be adopted in inquiry teaching [5]. One is that self-assessment and mutualevaluation among students may be carried out in terms of the standard, the other is the course of inquiry and to assessment results. Then the good mechanism of feedback, inspiration and punishment should be set up between two dimensions. To meet the demand teachers should monitor the inquiry course and grasp the evaluation scale in sight of prospect. Moreover, teachers should arrange all things and propose new inquiry issues. Then next inquiry activity man be appeared. Thus teachers should have more knowledge and stronger abilities.

After class teachers can leave some open and imaginative homework for students to inspire students' interests of autonomy, cooperation and inquiry. Teachers should objectively deal with the individual ability difference among students and assign the open homework moderately in groups.

There are many advantages about inquiry teaching. Inquiry is one of the instincts of children. Inquiry is also human's life instinct throughout his life. It is an important path for students to understand and know the word. Students can really grasp knowledge which they learn them by themselves. Inquiry would help students to protect their curiosity and desire for knowledge. Thus their scientific spirit and attitude can be developed and they will know how to cooperate and communicate. Also they can learn to listen and reflect to help them get knowledge and information autonomously. Moreover students will experience so many things including frustration and failure, success and excitement. These experiences will help them really understand the nature of science and the significance of science.

\section{ASSESSMENT OF TEACHING PRACTICE IN CLASS}

The assessment table of class teaching is quantitatively assessed from such prospects as fitness, Choice rationality, Guidance of teacher, students' adaptability to autonomous construction of knowledge [6]. The results are shown in Table 1 .

\section{TABLE I ASSESSMENT RESULTS}

\begin{tabular}{|c|c|c|}
\hline \multicolumn{1}{|c|}{ Assessment items } & $\begin{array}{c}\text { Comprehensive } \\
\text { evaluation (\%) }\end{array}$ & $\begin{array}{c}\text { Digital television } \\
\text { theory }\end{array}$ \\
\hline $\begin{array}{c}\text { Inquiry teaching } \\
\text { (A. suitable B. comparatively suitable C. unsuitable) }\end{array}$ & Suitability(A+B) & $97.2 \%$ \\
\hline $\begin{array}{c}\text { Choice of inquiry questions } \\
\text { (A. reasonable B. comparatively C. unreasonable) }\end{array} \quad$ Rationality(A+B) & $98.3 \%$ \\
\hline $\begin{array}{c}\text { Autonous construction of knowledge } \\
\text { (A. well B. comparatively C. bad) }\end{array}$ & Adaptability(A+B) & $90.5 \%$ \\
\hline $\begin{array}{c}\text { (A. much B. compation among students } \\
\text { Guidance of teachers }\end{array}$ & Cooperation(A+B) & $90.4 \%$ \\
\hline $\begin{array}{c}\text { (A. moderate B. comparatively C. poor) } \\
\text { (A. obvious B. comparatively C. not obvious) }\end{array}$ & Suitability(A+B) & $96.1 \%$ \\
\hline $\begin{array}{c}\text { Improvement of innovative ability } \\
\text { (A. obvious B. comparatively C. not obvious) }\end{array}$ & Distinctness(A+B) & $92.9 \%$ \\
\hline
\end{tabular}

\section{CONCLUSION}

The paper discusses some teaching problems of digital television system based on the traditional methods. Then the feasible research about teaching methods is studied and a new method called three-dimensional method is put forward. In brief, the new method can excite the learning interest and improve the comprehensive abilities of students so that the high quality talents will be trained for our country.

\section{REFERENCES}

[1] University of Post and Telecommunication Press, 2011 (In Chinese
[2] Yao Shanhua, Chen Qinghua. Probe into the Classroom + Field Teaching Method of Communication Specialty [J] . Sci-Tech Information Development \& Economy, 2008,3: 203-204 (In Chinese)

[3] Liu Peng, Yan Maohong. Assessment Strategies and Methods Based on Learning Outcomes in Engineering Inquiry-based education [J]. Research in Higher Education of Engineering. 2016,3. (In Chinese)

[4] Yingzi Wang, Peng Lin. Active and experiential Learning by Simulated Review of Design Scheme [J]. Proceeding of the 8th International CDIO Conference. Queensland University of Technology, 2012,7

[5] Lu Feng, Yilan Kang. Reform and Practice of Problem-learning Based Research- style Teaching [J]. Research in Higher Education of Engineering.2013, 4.

[6] Lu changping, Jiangrui, Deng qingshan. Construction of Assessment System of Inquiry Teaching [J].China University Teaching. 2013.6 (In Chinese) 